\title{
The Research on Technical Qualifications of Railway Piggyback Transportation in China
}

\author{
Yueting Wang, Zuoyi Liu \\ School of Traffic and Transportation, Beijing Jiaotong University, Beijing 100044, China
}

\begin{abstract}
The piggyback transportation is still blank in China. The paper describes the loading plans of the piggyback transportation and confirms the adaptation of railway gauge. Finally, the paper calculates the forces which act on the truck on the moving piggyback flat car, and tests the stability of van-body truck. Based on the above studies, the fastening plans of piggyback transportation are designed.
\end{abstract}

KEYWORD: Piggyback transportation; Loading plan; Railway clearance adaptation; Fastening plan

\section{INTRODUCTION}

Piggyback transportation is that a truck containing the goods places on the flat wagon, which belongs to multimodal transportation. It has the features of economy and convenience, safety and reliability, energy efficiency and environment protection. With the improvement of the layout of railway network in China, freight transportation capacity has been effectively improved. Therefore, the opportunity of carrying piggyback transportation is ripe. The literatures (Yu Ning, 1981; Qili Wang, 1985; Yusheng Li, 1993; Aimin Wang, 2007) described the development of foreign piggyback transportation and proposed preparation of technical conditions. The literatures (Guoping Zhang, 2007; Jun Jin, 2004) pointed out the necessity of developing the piggyback transportation and discussed the key issues. Through reading large numbers of documents, combining theory with practice, the paper designs the loading plans of piggyback transportation which takes advantage of the existing rail flat car and designs the piggyback transportation fastening plans.

\section{DESIGN OF RAILWAY PIGGYBACK}

\section{TRANSPORTATION LOADING UNDER THE}

\section{EXISTING CONDITIONS}

Vehicles selection. The piggyback transportation is very quick and convenient. When selecting existing railway cars should firstly consider the model of speed raising bogies (the construction speed is 120 $\mathrm{km} / \mathrm{h}$ ). Conforming to the condition of existing railway ordinary flat cars mainly including $\mathrm{N}_{17 \mathrm{~K}}$, $\mathrm{N}_{17 \mathrm{AK}}, \mathrm{N}_{17 \mathrm{GK}}, \mathrm{NX}_{17 \mathrm{~K}}, \mathrm{NX}_{17 \mathrm{AK}}, \mathrm{NX}_{17 \mathrm{BK}}, \mathrm{NX}_{17 \mathrm{BH}}$, $\mathrm{NX}_{70}, \mathrm{NX}_{70 \mathrm{~A}}$, etc. To simplify the case, choosing
$\mathrm{NX}_{70}$ flat wagon loads the trucks during piggyback transportation. The basic parameters of $\mathrm{NX}_{70}$ flat are shown as Table 1.

Table 1 The basic technical parameters of NX70 flat

\begin{tabular}{cc}
\hline Body Parts & Parameters \\
\hline Tare weight $(\mathrm{t})$ & 23.8 \\
Load weight $(\mathrm{t})$ & 70 \\
Body frame length $(\mathrm{mm})$ & 15400 \\
Body frame width $(\mathrm{mm})$ & 2960 \\
Bogie center distance $(\mathrm{mm})$ & 10920 \\
Floor vehicle away from the & 1216 \\
track surface high $(\mathrm{mm})$ & 738 \\
Empty high center of gravity (mm) & 4 \\
Axle number & wood \\
Vehicle floor material &
\end{tabular}

Trucks are divided into heavy truck, medium truck, light truck and mini truck in China. Miniature and light truck is mainly used for short distance transportation, and the length of the vehicle is smaller. So they are not suitable for railway piggyback transportation.

Table 2 The basic technical parameters of trucks

\begin{tabular}{ccccc}
\hline Number & $\begin{array}{c}\text { Number } \\
\text { of axle } \\
\text { /wheel }\end{array}$ & $\begin{array}{c}\text { Maximum } \\
\text { length } * \text { width } \\
* \text { height }(\mathrm{mm})\end{array}$ & $\begin{array}{c}\text { Rated load } \\
\text { capacity } \\
(\mathrm{kg})\end{array}$ & $\begin{array}{c}\text { Maximum } \\
\text { total mass } \\
(\mathrm{kg})\end{array}$ \\
\hline A & $4 / 12$ & $\begin{array}{c}11980 \times \\
2550 \times 3990 \\
11990 \times\end{array}$ & 20700 & 31000 \\
B & $3 / 8$ & $\begin{array}{c}2550 \times 3990 \\
7648 \times\end{array}$ \\
C & $2 / 6$ & 16965 & 25000 \\
$2550 \times 3655$ & 11000 & 16000 \\
\hline
\end{tabular}


Loading plans design. The gravitational projection of A and B trucks fall on the vertical and horizontal centerline of $\mathrm{NX}_{70}$ flat wagon. This truck is not beyond the flat wagon car side, and is shown as fig. 1 and fig.2.

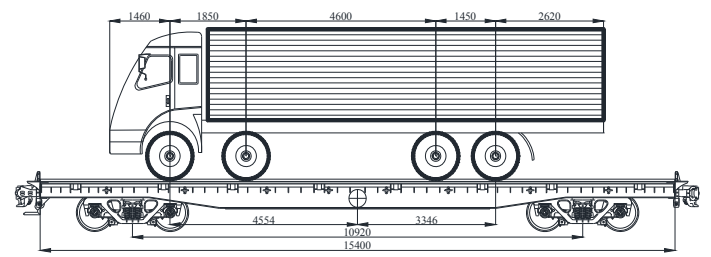

Fig. 1 The loading plan 1

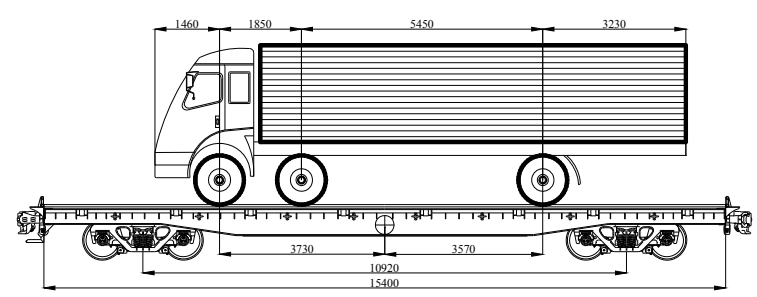

Fig. 2 The loading plan 2

The two $\mathrm{C}$ trucks forward loading, the front truck (set to I car) is aligned with flat wagon car side of the railway, and the rear of truck (set to II car) is aligned with the end of the flat wagon.

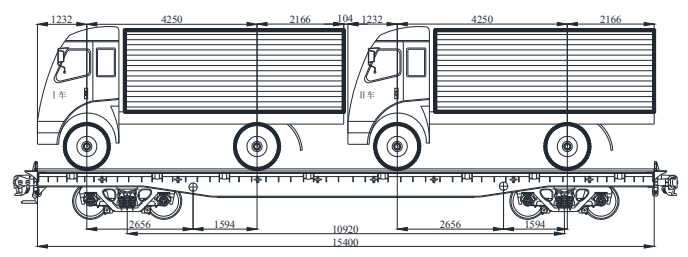

Fig. 3 The loading plan 3

\section{LOADING PLAN GAUGE ADAPTATION ANALYSIS}

For the truck was approximately regarded as the cross-sectional cuboid. From Table 2, the width of these trucks is similar, focusing on both sizes $2500 \mathrm{~mm}$ and $2550 \mathrm{~mm}$. The truck is placed on the flat wagon, which does not exceed the width of flat cars.

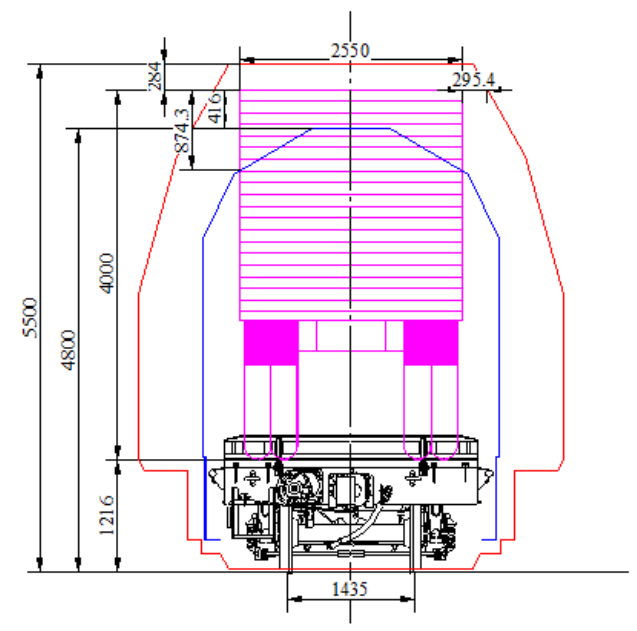

Fig. 4 The adaptability to gauge for normal lines of piggyback transportation

From above, the maximum dimensions truck is loaded on $\mathrm{NX}_{70}$ flat car, whose height exceeds the maximum rolling stock clearance about $874.3 \mathrm{~mm}$ that belongs to the super overrun. If the piggyback carried in normal line, which is regarded as out-ofgauge freight. Therefore, the normal line is not suitable to carry out piggyback transportation under the existing conditions.

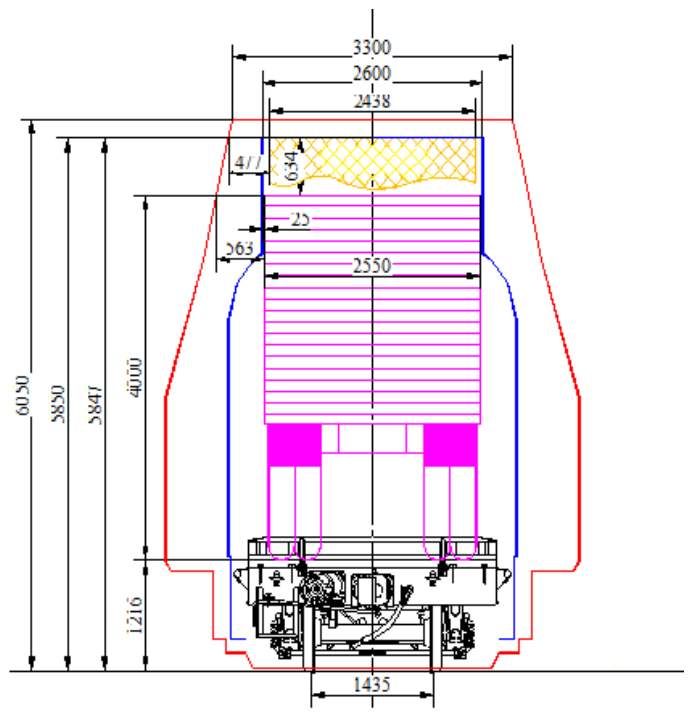

Fig. 5 The adaptability to gauge for double-stack transportation corridor of piggyback transportation

Carried piggyback on the double-stack transportation corridor, its adaptability gauge is shown as figure 5. Through drawing calculation shows that $\mathrm{NX}_{70}$ flat cars carrying the maximum size of truck doesn't exceed the double-stack container transportation loading gauge, so the channels meet the clearance requirements when carrying out railway piggyback transportation. At present, the railway company has planned 10 double-stack container transportation lines, and put three into operation. 


\section{DESIGN OF RAILWAY PIGGYBACK}

TRANSPORTATION FASTENING PLAN

Calculation of the force acting on the truck in carriage process. There are 5 kinds of forces that mainly includes longitudinal inertia force, lateral inertia force, the vertical inertia force, wind and friction (friction including longitudinal and transverse friction) acting on the truck during the moving train. The calculation methods of the five kinds of force values are shown below.

$\mathrm{t}_{0}=0.0012 \mathrm{Q}_{\mathrm{Z}}^{2}-0.32 \mathrm{Q}_{\mathrm{Z}}+29.85$

$\mathrm{T}=\mathrm{t}_{0} \mathrm{Q}$

While

$\mathrm{t}_{0}$ - Unit weight of the goods suffers longitudinal inertia force $(\mathrm{kN} / \mathrm{t})$;

$\mathrm{Q}_{z}$ - The total weight of heavy vehicles $(\mathrm{kN})$;

$T$-Longitudinal inertia force $(\mathrm{kN})$;

Q-Truck weight $(\mathrm{t})$.

$\mathrm{n}_{0}=2.82+2.2 \mathrm{a}^{\prime} / 1$

$\mathrm{N}=\mathrm{n}_{0} \mathrm{q}_{\mathrm{c}}$

While

$n_{0}$-Unit weight of the goods suffers lateral inertia force $(\mathrm{kN} / \mathrm{t})$;

$a^{\prime}$ - The longitudinal offset of the center of the truck from the center of the truck $(\mathrm{mm})$;

$l$-Railway car pin distance $(\mathrm{mm})$;

$N$-Lateral inertia force $(\mathrm{kN})$;

$\mathrm{q}_{\mathrm{c}}=3.54+3.78 \mathrm{a}^{\prime} / 1$

$\mathrm{Q}_{\mathrm{c}}=\mathrm{q}_{\mathrm{c}} \mathrm{Q}$

While

$q_{c}$-Unit weight of the goods suffered vertical inertia force $(\mathrm{kN} / \mathrm{t})$;

$Q_{c}$-Vertical inertia force $(\mathrm{kN})$;

$\mathrm{W}=\mathrm{qF}$

While

$q$-Lateral wind pressure, calculated by $0.49 \mathrm{kN} / \mathrm{m}^{2}$

$F$-Lateral windward side projects area $\left(\mathrm{m}^{2}\right)$;

$W$-Wind force $(\mathrm{kN})$;

$\mathrm{F}^{\prime}=9.8 \mu \sum \mathrm{Q}_{\mathrm{i}}$

$F^{\prime \prime}=\mu\left(9.8 Q-Q_{c}\right)$

While

$\mathrm{F}^{\prime}$ - Longitudinal friction $(\mathrm{kN})$;

$\mathrm{F}^{\prime \prime}$-Lateral friction $(\mathrm{kN})$;

$\mathrm{Q}_{\mathrm{i}}$-Truck loaded, the i-th braked wheel suffers loading force $(\mathrm{kN})$;

$\mu$-Friction coefficient, taking rubber tires and wooden flooring coefficient, 0.63 ;

There are 3 kinds of loading plans that the ruck suffers force value according to truck and rail flat wagon technical parameters, as shown as table 3.
Table 3.The calculation of force value

\begin{tabular}{ccccccc}
\hline Plan & $\mathrm{T}(\mathrm{kN})$ & $\begin{array}{c}\mathrm{N} \\
(\mathrm{kN})\end{array}$ & $\begin{array}{c}\mathrm{Qc} \\
(\mathrm{kN})\end{array}$ & $\begin{array}{c}\mathrm{W} \\
(\mathrm{kN})\end{array}$ & $\begin{array}{c}\mathrm{F}^{\prime} \\
(\mathrm{kN})\end{array}$ & $\begin{array}{c}\mathrm{F}^{\prime \prime} \\
(\mathrm{kN})\end{array}$ \\
\hline 1 & 478.51 & 87.42 & 109.74 & 23.42 & 111.13 & 122.26 \\
2 & 414.31 & 70.50 & 88.50 & 23.44 & 67.91 & 98.60 \\
$3-$ & 295.03 & 57.41 & 77.75 & 13.70 & 61.74 & 49.80 \\
I & & & & & & \\
$3-$ & 295.03 & 57.82 & 78.46 & 13.70 & 61.74 & 49.35 \\
II & & & & & & \\
\hline
\end{tabular}

Truck stability calculation. From three aspects which are overturning, rolling and horizontal movement analyze the stability of piggyback transportation. Calculation methods are shown as follows.

$\eta_{\mathrm{q}}=\frac{9.8 \mathrm{Qb}}{\mathrm{Nh}+\mathrm{Wh}_{\mathrm{f}}} \geqslant 1.25$

\section{While}

$\eta_{q}$-Lateral overturning stability coefficient;

$\mathrm{b}$-The distance between truck Center where the longitudinal vertical plane and the transverse overturning points $(\mathrm{mm})$, where takes the half of minimum track width.

$\mathrm{h}$ - The height between the truck center of gravity point and horizontal transverse overturning point, where takes $2050 \mathrm{~mm}$;

$\mathrm{h}_{\mathrm{f}}$-The height between the point of the wind and the transverse overturning point $(\mathrm{mm})$, where the half of truck height is taken.

$\eta_{\mathrm{g}}=\frac{9.8 \mathrm{Qa}}{\mathrm{T}\left(\mathrm{D} / 2-\mathrm{h}^{\prime}\right)} \geqslant 1.25$

While

$\eta_{\mathrm{g}}$-Longitudinal rolling stability coefficient;

$\mathrm{a}-$ The distance between the gravity of truck on transverse vertical plane and the contacted point of mask and wheel (mm).

D-The diameter of truck wheel, where takes $1100 \mathrm{~mm}$;

$\mathrm{h}$ '- The height between the point which mask or triangular wood contact the wheel of truck and the lowest point since the level, where takes $200 \mathrm{~mm}$.

$$
\begin{aligned}
& \Delta T=\mathrm{T}-\mathrm{F}^{\prime} \quad(12) \\
& \Delta N=1.25(\mathrm{~N}+\mathrm{W})-\mathrm{F}^{\prime \prime}(13) \\
& \text { While }
\end{aligned}
$$

$\Delta T$ - The force $(\mathrm{kN})$ preventing the vehicle from moving in the longitudinal direction of the reinforecement device (material).

$\Delta N$ - The force $(\mathrm{kN})$ preventing the vehicle from moving in the lateral direction of the reinforecement device (material).

Three kinds of plans are calculated respectively of the stability of the truck, and shown as table 4 . 
Table 4 The calculation of stability of each loading plan

\begin{tabular}{ccccc}
\hline Plan & $\eta_{q}$ & $\eta_{g}$ & $\Delta T(\mathrm{kN})$ & $\Delta N(\mathrm{kN})$ \\
\hline 1 & 1.25 & 7.00 & 367.38 & 16.29 \\
2 & 1.19 & 6.90 & 346.39 & 18.83 \\
3- I & 0.99 & 3.20 & 233.29 & 39.08 \\
3- II & 0.98 & 3.20 & 233.29 & 40.04 \\
\hline
\end{tabular}

The 3 kinds of loading plans won't move in the vertical direction without pulling pull reinforcement, but they will move horizontally. The plan 1 will not occur lateral capsized, but plan 2 and plan 3 may occur.

Reinforcement method and strength calculation of loading plan. According to loading plans, piggyback transportation suit pulling reinforcement. Because the gravity of vehicle is located in the central vehicle, we should take the symmetric stretch.

$\mathrm{S}_{1}=\frac{\Delta \mathrm{T}}{\mathrm{nAC}} \sqrt{\mathrm{BO}^{2}+\mathrm{AC}^{2}+\mathrm{BC}^{2}}$

$\mathrm{S}_{2}=\frac{\Delta \mathrm{N}}{\mathrm{nBC}} \sqrt{\mathrm{BO}^{2}+\mathrm{AC}^{2}+\mathrm{BC}^{2}}$

$\mathrm{S}_{3}=\frac{1.25\left(\mathrm{Nh}+\mathrm{Wh}_{\mathrm{f}}\right)-9.8 \mathrm{Qb}}{\mathrm{n}\left(\mathrm{l}^{\prime}+\mathrm{BC}\right) \mathrm{BO}} \sqrt{\mathrm{BO}^{2}+\mathrm{AC}^{2}+\mathrm{BC}^{2}}$

While

$S_{1}$ - The force preventing truck from longitudinal movement $(\mathrm{kN})$;

$S_{2}$ - The force preventing truck from lateral movement $(\mathrm{kN})$;

$S_{3}$ - The force preventing truck from lateral rolling $(\mathrm{kN})$;

$\mathrm{n}$ - The number of ropes in the same direction;

$\mathrm{AC}$ - The distance between the rope tied to the node on the transversely vertical plane and the tied point of the truck $(\mathrm{mm})$.

$\mathrm{BC}$ - The distance between the rope tied to the node on the longitudinally vertical plane and the tied point of the truck $(\mathrm{mm})$.

BO-The height between the node on the truck and the surface of vehicle floor $(\mathrm{mm})$.

$l^{\prime}$-The distance between the transverse over turning point of the truck and the rope tied to the node on the longitudinally vertical plane, which can be approximated to 0 .

The rope not only prevents truck vertical movement, but also prevents lateral movement when drafting reinforcement, so each rope should bear the force as the following formula.

$\mathrm{S} \geqslant \max \left\{\mathrm{S}_{1}, \mathrm{~S}_{2}, \mathrm{~S}_{3}\right\}$

Table 5 Calculation results of pulling force value

\begin{tabular}{cccc}
\hline Plan & $\mathrm{S}_{1}(\mathrm{kN})$ & $\mathrm{S}_{2}(\mathrm{kN})$ & $\mathrm{S}_{3}(\mathrm{kN})$ \\
\hline 1 & 68.97 & 8.34 & 0 \\
2 & 97.55 & 14.46 & 15.73 \\
3- I & 66.09 & 28.63 & 49.65 \\
3- II & 66.09 & 29.33 & 51.06 \\
\hline
\end{tabular}

According to the calculation wire rope should bear pulling force to determine the specifications of the rope. The allowable tensile takes $50 \%$ of the breaking force, which is the breaking force not less than $2 \mathrm{~S}$ when using wire rope to reinforce. The specification of wire rope is shown as the table 6 .

Table 6 The specification of wire rope

\begin{tabular}{ccc}
$\begin{array}{c}\text { Diameter of wire } \\
\text { rope }(\mathrm{mm})\end{array}$ & $\begin{array}{c}\text { Minimum break- } \\
\text { ing force }(\mathrm{kN})\end{array}$ & $\begin{array}{c}\text { Allowable tensile } \\
\text { force }(\mathrm{kN})\end{array}$ \\
\hline 17 & 153.27 & 76.63 \\
18 & 166 & 83 \\
20 & 205 & 102.5 \\
24 & 295 & 147.5 \\
26 & 346 & 173 \\
\hline
\end{tabular}

Plan 1 should use the wire rope with $\varphi 17 \mathrm{~mm}$ to reinforce though the table 6 , and the fastening plan is shown as figure 6 .

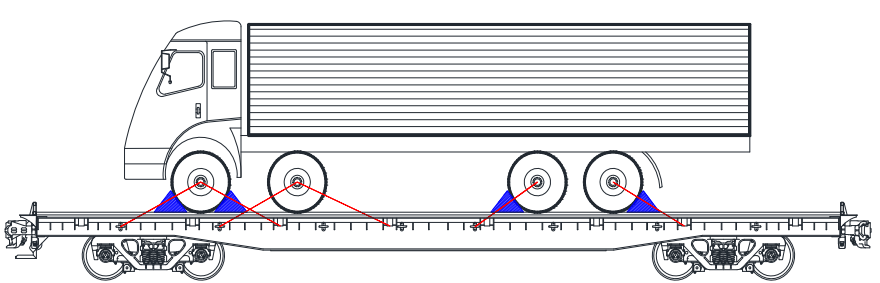

Fig. 6 The fastening plan of loading plan 1

Plan 2 should use the wire rope with $\varphi 20 \mathrm{~mm}$ to reinforce though the table 6 , and the fastening plan is shown as figure 7 .

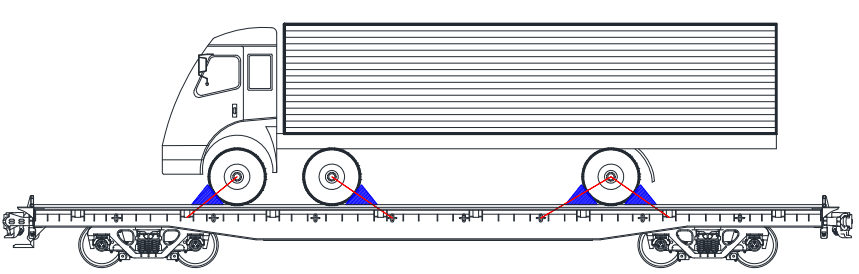

Fig. 7 The fastening plan of loading plan 2

Plan 3 should use the wire rope with $\varphi 20 \mathrm{~mm}$ to reinforce though the table 6 , and the fastening plan is shown as figure 8 .

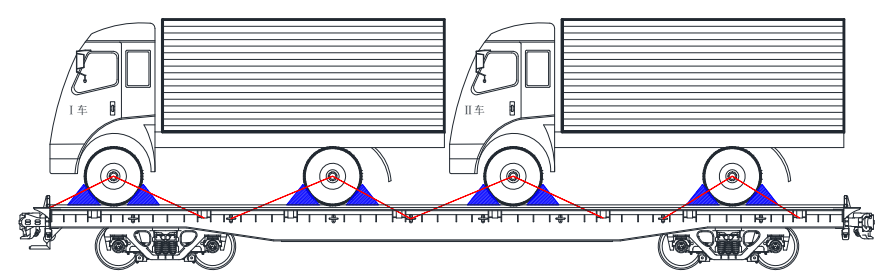

Fig. 8 The fastening plan of loading plan 3

The front and rear wheel of the truck where front and rear sides should be covered respectively used by triangular wood, which is fixed on the floor. The 
truck keeps locking the doors and windows, braking device, and the transmission is in gear 1 position velocity, while the automatic handle fixed with wire after loading. The rearview mirror is folded back and fixed steadily. The rope and the truck contact edges should take preventive measures.

\section{SUMMARY}

Railway piggyback transportation is a organizational mode to realize door to door transportation which conforms to the reformatory direction of the freight organization and enhances the service level of railway freight transportation. The piggyback transportation selects the trucks carried on $\mathrm{NX}_{70}$ railway flat cars. The designed loading plans in the paper meet the basic technical requirements. According to the analysis of gauge, piggyback transportation is suitable for double-stack container transportation corridors under the existing conditions.

\section{REFERENCES}

Aimin Wang, Liang Lin. Junction Railway Piggyback - Container Transportation Special Vehicle Discussion and vision [J] railway vehicles, 2007, 45 (10): 24-27.

Guoping Zhang, Ran Wei, Jianrui Miao. Swiss piggyback rail transportation intermodal transportation in the application of [J] railway vehicles, 2007,45 (1): 24-27.

Jun Jin, Qing Wang, Hong Yan, et. Play the comparative advantages of rail transportation logistics system to build rail transportation as the core [J].Railway freight:2004(2):19-22.

Qili Wang. French rail piggyback transportation vehicle development before [J]. Foreign Rolling Stock, 1985

Yusheng Li. European rail-cum piggyback truck design [J] Foreign railway vehicles, 1993 (2): 5-7.

$\mathrm{Yu}$ Ning, zhicai shi. United States piggyback transportation and the new vehicle development[J]. Freight railway vehicles, 1981(1). 